\title{
La construcción «exprés» de un paisaje aterrazado habitable en un medio inhóspito (Sierra de Salinas, Alicante)
}

\author{
The "Express" Construction of a Habitable Terraced Landscape in an \\ Inhospitable Environment (Sierra de Salinas, Alicante)
}

\author{
Ascensión Padilla Blanco* \\ Universidad de Alicante \\ http:/ / orcid.org/0000-0001-9420-9136 \\ ma.padilla@ua.es \\ Pablo Giménez Font \\ Universidad de Alicante \\ http://orcid.org/0000-0002-1171-715X \\ pablo.gimenez@ua.es
}

\author{
Juan Antonio Marco Molina \\ Universidad de Alicante \\ http:/ / orcid.org/0000-0003-3431-0499 \\ ja.marco@ua.es \\ Ángel Sánchez Pardo \\ Universidad de Alicante \\ https:/ / orcid.org/0000-0002-0604-5766 \\ a.sanchez@ua.es
}

Recibido: 15/06/2020; Revisado: 17/08/2020; Aceptado: 22/10/2020

\section{Resumen}

La Colonia Agrícola de la Sierra de Salinas es una de las dieciocho que se crearon en España a principios del siglo xx tras la aprobación de la «Ley de colonización y repoblación interior» de 1907. En esta investigación, se analiza el contenido del proyecto y se valora su viabilidad con las herramientas actuales que ofrece la administración pública de la Generalitat Valenciana y que son de obligada consulta para cualquier actuación territorial. Espacio potencialmente forestal, pendientes acusadas, pedregosidad elevada y escasa fertilidad fueron superadas por los colonos en su intento de hacer habitable un territorio que no lo era.

Palabras clave: Colonia agrícola, terrazas de cultivo, piedra seca, vida colonial, Sierra de Salinas.

\begin{abstract}
The Agricultural Colony of Sierra de Salinas is one of the eighteen that were created in Spain in the early twentieth century after the adoption of the "Law of Colonization and Internal Repopulation" in 1907. In this research, the content of the project is analysed and its feasibility assessed. The assessment is carried out with the current tools offered by the public administration of the Generalitat Valenciana, as said tools are subject to mandatory consultation prior to any territorial action. Potential forest land, steep slopes, elevated stoniness and low fertility were all overcome by the settlers in their attempt to make habitable a territory that previously was not.
\end{abstract}

Key words: Agricultural Colony, Terraced Fields, Dry Stone, Colonial Life, Sierra de Salinas.

*Autor de correspondencia / Corresponding author. 
La construcción «exprés» de un paisaje aterrazado habitable...

\section{INTRODUCCIÓN}

El éxodo rural hacia las grandes ciudades españolas, Madrid y Barcelona, $\mathrm{y}$ al extranjero, Argentina, era tan alarmante a principios del siglo xx que el Ministerio de Fomento intentó ponerle freno, al tiempo que trató de satisfacer las aspiraciones del campesinado con la «Ley de colonización y repoblación interior» del 30 de agosto de 1907. Ésta fue concebida como un ensayo, por lo que se aplicaría a montes y terrenos enajenables del Estado, a bienes abandonados, baldíos o incultos, y de dominio público. Únicamente, de modo excepcional, afectaría a montes de utilidad pública. Por lo tanto, en su mayoría, eran espacios con una dedicación forestal que requerían una gran transformación para su puesta en cultivo, así como una ardua tarea por parte de los colonos.

Cada colonia creada se basaría en la unidad familiar (colono, esposa y descendencia), la cooperación mutua, el apoyo económico y técnico del Estado y la creación de una asociación cooperativa como vínculo entre el gobierno estatal y los colonos. La importancia otorgada a la familia campesina en esta ley se relaciona con el catolicismo social; de ahí también los vínculos que se intentan promover y potenciar (PANIAGUA, 1992) con la configuración de los espacios comunes y con la creación de una cooperativa. La extensión de cada unidad de explotación estaba determinada por la superficie necesaria para sustentar económicamente a cada familia, por lo que tampoco aseguraba un nivel de vida con excedentes suficientes como para poder comerciar $\mathrm{u}$ obtener beneficios extras. De hecho, estos se entregaban a la cooperativa y se repartían de manera equitativa o se ayudaba a quienes no habían tenido buena producción. Cada lote era entregado a quienes declaraban y justificaban ser totalmente pobres. No toda la superficie era destinada al aprovechamiento agrícola, sino que una cuarta parte tenía dedicación forestal (Ministerio de Fomento, 1907). Los productos cultivados estaban establecidos en el estudio técnico elaborado previamente a la transformación del espacio, el cual era realizado por un ingeniero agrónomo, vinculado a las Juntas Provinciales de Colonización y Repoblación Interior. Solo a partir del quinto año, se podía optar a la propiedad de la tierra, siempre y cuando se hubiera puesto en cultivo y fuera rentable. Las colonias sólo podían ser heredadas por un descendiente de la familia; de este modo se aseguraba la indivisibilidad del lote.

Dieciocho colonias fueron constituidas en España desde la promulgación de esta ley hasta 1932 (CANALES, 1998: 346) y la mayoría de ellas fracasaron porque eran espacios potencialmente forestales y con suelos de escasa productividad agrícola. Uno de estos «ensayos» fue la Colonia Agrícola de la Sierra de Salinas (Figura 1), ubicada en el municipio de Villena (Alicante, España). El proyecto se redactó en 1910 y el reparto de lotes fue el 21 de abril de 1914 en el Ayuntamiento de Villena y con presencia del alcalde y del delegado de la Junta Central de Colonización. El mismo día se constituyó la Asociación Cooperativa de la Colonia Agrícola de la Sierra de Salinas, tal y como se establecía por ley.

El presente estudio se centra en justificar las causas que demuestran la inviabilidad del proyecto y que, seguramente, fueron obviadas, probablemente por presiones políticas, en el proyecto de colonización agrícola de este espacio realizado por el ingeniero agrónomo Luis Beneyto. Así mismo, este documento pretende ser un homenaje a todas esas familias que transformaron en pocos años parte de este espacio montano y forestal en laderas aterrazadas con muretes de piedra seca y lucharon por subsistir y hacer habitable un medio inhóspito. 


\section{METODOLOGÍA}

La información recopilada para esta aportación científica se ha obtenido a partir de tres tipos de fuentes: bibliográfica-documental, cartográfica y entrevistas directas o cedidas en archivos audiovisuales realizadas a los descendientes de los colonos. En la primera de ellas, ha sido fundamental la consulta de la memoria y planos del Proyecto de Colonización del Monte «Sierra de Salinas» (Villena) Alicante (Junta Central de Colonización y Repoblación Interior, 1910) ya que ha aportado la información necesaria para conocer la superficie detallada que se deseaba transformar, los diferentes usos a los que se destinaría, las características y propiedades del terreno (Figura 2) y, lo más valioso, la representación cartográfica realizada por el ingeniero agrónomo Luis Beneyto (Figura 3).

Para caracterizar y justificar la escasa rentabilidad agrícola de la colonia de Salinas, ha sido necesaria la consulta de la capa de información sobre capacidad de usos del suelo, así como toda la cartografía básica y de pendientes, disponibles en la Infraestructura Valenciana de Datos Espaciales (IDEV) de la Generalitat Valenciana. ${ }^{1}$ Estas capas de información se han cruzado con el plano georreferenciado del informe técnico o memoria con el fin de obtener una representación cartográfica de la superficie realmente productiva de la colonia y que, por tanto, tenía posibilidades de éxito tras ejecutar el proyecto. Este análisis cartográfico se ha realizado con QGIS 3.4. De este modo, podemos verificar la viabilidad de la propuesta de transformación de 1910.

Los testimonios de cómo trabajaron y habitaron los colonos este espacio se han obtenido a través de entrevistas mantenidas con sus descendientes, de manera directa o indirecta. En esta segunda situación, ha sido gracias al visionado de dos vídeos que se elaboraron con motivo del centenario de la Colonia de Salinas (1914-2014). Este material audiovisual es fruto de la muestra etnográfica de la casa del guarda, en la que se recreó el mobiliario en sus estancias y la vestimenta de los colonos, así como de una exposición en la Casa de la Cultura de Villena que se realizó con la colaboración de la Universidad de Alicante y el Museo Arqueológico José María Soler. ${ }^{2}$ Ambos actos tuvieron lugar a lo largo del año 2014. Pero, sobre todo, han sido de gran valía los datos y documentación aportada por la junta directiva de la actual Asociación de Colonos y Patrimonios Familiares de la Sierra de Salinas de Villena. ${ }^{3}$

\section{RESULTADOS}

\subsection{El significado de las cifras en el Proyecto de Colonización del monte «Sierra de Salinas»}

La aplicación de la «Ley de colonización y repoblación interior» del 30 de agosto de 1907 en la Sierra de Salinas fue posible gracias a que ésta pasó a ser

1 Infraestructura Valenciana de Dades Espacials [en línea]. Disponible en: http://www.idev.gva.es [Consulta: 17/08/2020].

2 Muestra etnográfica en la «Casa del Guarda». Colonia Sierra de Salinas, Villena, Alicante [en línea]. Disponible en: https://www.youtube.com/watch?v=HePVZvB0SL0 [Consulta: 17/08/2020].

3 Blog de Colonos Agrícolas y Patrimonios Familiares de la Sierra de Salinas de Villena [en línea]. Disponible en: https://coloniasierrasalinasvillena.blogspot.com [Consulta: 17/08/2020]. 
monte enajenable en 1887 por aplicación del RD de 27 de febrero (CANALES, 1986: 43) con una extensión de 3500 ha, incluida la superficie, 1500 ha, de la «Sierra de Salinas (el Coto)» según reza en la Clasificación General de los Montes Públicos de 1859 (Ministerio de Agricultura, Pesca y Alimentación, 1990). El proyecto del agrónomo Luis Beneyto fue realizado en 1910 y el monte «Coto de la Sierra de Salinas» pasó a manos de la Junta Central de Colonización y Repoblación Interior al año siguiente (TARRUELLA, 1998: 487). La memoria ofrece un estudio detallado de las características climáticas, de las propiedades de los suelos, análisis topográfico junto a escorrentía superficial y procesos de infiltración del agua. Con todo ello, se creó una tipología de tierras más o menos productivas según un criterio de rentabilidad agrícola y se delimitaron cartográficamente los lotes, teniendo en cuenta que estos debían de contener tres partes de superficie agrícola y una cuarta parte forestal.

La tipología definida a partir de la calidad productiva de las tierras para la Sierra de Salinas diferenciaba tres categorías y tamaños de lotes: primera $(7,5699$ ha), segunda (11,2510 ha) y tercera (20,4392 ha); de modo que, a mayor tamaño, menor rentabilidad agraria. El área máxima de cada lote no podía superar las 20 ha según estipulaba la ley de 1907; sin embargo, en esta colonia se permitió sobrepasar este umbral por compensación, ya que las pendientes debían de ser salvadas con muretes de piedra seca, con el fin de anular la erosión y poder obtener suelo agrícola, lo que suponía una pérdida de superficie.

Con todo, se definieron grandes unidades según su potencialidad productiva y cobertura del suelo y, dentro de cada una de ellas, se calculó la superficie de las tres categorías según se muestra en la tabla 1.

TABLA 1

Distribución y clasificación de la superficie proyectada de la Colonia Agrícola Sierra Salinas

\begin{tabular}{|c|c|c|}
\hline \multirow{3}{*}{$\begin{array}{l}\text { Parcelas colonizables para el cultivo } \\
\text { agrario, sin pinos }\end{array}$} & $1^{a}$ categoría & 13,9528 ha \\
\hline & $2^{a}$ categoría & $\begin{array}{l}\text { 90,5996 ha, de las cuales: } \\
\text { Edificios comunales: } 1,7232 \text { ha } \\
\text { Parcela de experimentación: } \\
5,3428 \text { ha, de las que } 1,4800 \text { ha } \\
\text { eran de pinar que no se taló. }\end{array}$ \\
\hline & $3^{\mathrm{a}}$ categoría & $\begin{array}{l}511,2654 \text { ha } \\
\text { Caracterizadas como "pequeñas } \\
\text { mesetas de las cumbres" }\end{array}$ \\
\hline TOTAL cultivo agrario, sin pinos & \multicolumn{2}{|l|}{615,8178 ha } \\
\hline \multirow{3}{*}{$\begin{array}{l}\text { Parcelas colonizables para el cultivo } \\
\text { agrario, con pinos }\end{array}$} & $1^{\text {a }}$ categoría & 9,5548 ha \\
\hline & $2^{a}$ categoría & 63,5300 ha \\
\hline & $3^{\mathrm{a}}$ categoría & $\begin{array}{l}163,3468 \text { ha } \\
\text { Caracterizadas como "pequeñas } \\
\text { mesetas de las cumbres" }\end{array}$ \\
\hline
\end{tabular}


Ascensión Padilla, Juan Antonio Marco, Pablo Giménez y Ángel Sánchez

\begin{tabular}{|l|l|}
\hline TOTAL cultivo agrario, con pinos & $\mathbf{2 3 6 , 4 3 1 6}$ ha \\
\hline $\begin{array}{l}\text { Parcelas colonizables para el } \\
\text { aprovechamiento forestal, con pinos }\end{array}$ & $217,9221 \mathrm{ha}$ \\
\hline $\begin{array}{l}\text { Parcelas colonizables para el } \\
\text { aprovechamiento forestal, sin pinos }\end{array}$ & $270,8464 \mathrm{ha}$ \\
\hline TOTAL aprovechamiento forestal & $\mathbf{4 8 8 , 7 6 8 5} \mathrm{ha}$ \\
\hline $\begin{array}{l}\text { Parcelas rocosas inútiles para ambos } \\
\text { cultivos }\end{array}$ & $\mathbf{2 1 , 7 7 3 0 \text { ha }}$ \\
\hline TOTAL superficie colonia agrícola Sierra de Salinas: $\mathbf{1 . 3 6 2 , 7 9 0 9}$ ha \\
\hline
\end{tabular}

Fuente: Junta Central de Colonización y Repoblación Interior, 1910. Elaboración propia.

Teniendo en cuenta la información ofrecida en esta tabla, podríamos deducir que las tierras más aptas para un uso agrícola son las consideradas de primera categoría en la unidades denominadas como "parcelas colonizables para el cultivo agrario»; sin embargo, en la lectura de la memoria, se especifica que son únicamente las 104,5524 ha de la primera y segunda categoría de la unidad «parcelas colonizables para el cultivo agrario, sin pinos» ubicadas en el fondo del valle y con un contenido edáfico de sílice, arcilla, cal y elevado porcentaje de humus. Por lo tanto, del total de 852,2494 ha consideradas como aptas, solo el $12,27 \%$ lo era realmente según el proyecto o informe técnico (Gráfico 1). Es evidente, tras el análisis de estos datos, que el éxito de la transformación agrícola era imposible e, incluso, se podría tildar de locura. Sólo intereses políticos lo justifican. Un monte dedicado a la extracción de leñas y maderas (IBÁÑEZ, 1985: 55, CARPena et al., 2016), al menos datada desde el siglo XVI (PADILlA, 2000: 307) y del que la propia memoria de la Junta Central de Colonización y Repoblación Interior (1910) reconocía entre líneas que, antes de la actuación, había presencia de pinos, matorral y era potencialmente de uso forestal un total de 1.341,0179 ha, es decir el 98,4\% de la superficie total de la Colonia Agrícola de la Sierra de Salinas (Gráfico 2), difícilmente podría dedicarse a la agricultura más de la mitad (852,2494 ha= $64,24 \%)$.

\section{GRÁFICO 1}

Distribución porcentual de las tierras dedicadas a uso agrícola según su fertilidad en la Colonia Sierra Salinas

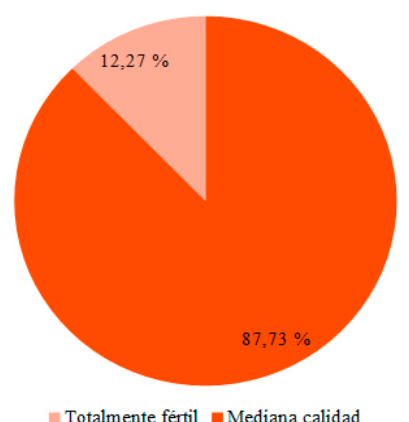

Fuente: Junta Central de Colonización y Repoblación Interior (1910). Elaboración propia. 
Además, se podría formular la cuestión de cuántos lotes, de los 49 que se obtuvieron y repartieron, eran rentables según la información de la tabla 1, es decir, aquellas hectáreas que se destinarían al cultivo, exceptuando la superficie dedicada a edificios comunales y parcela de experimentación. Si consideramos una gradación de mayor fertilidad a menor, repartida entre las tres categorías diferenciadas, obtenemos que solo 3 lotes tendrían asegurada la productividad, ubicados en el fondo del valle; 13 lotes serían medianamente productivos y más de la mitad, 33, presentarían serias dificultades de optimizar los recursos edáficos (Tabla 2). Pero ¿y si se aplican las descripciones y características redactadas en la memoria? En dicho contenido, se indica que solo las hectáreas de la primera y segunda categoría de la unidad de «parcelas colonizables para el cultivo agrario, sin pinos» son realmente las que poseen unas propiedades edáficas muy aptas para la agricultura. En este caso, solo unos 9 lotes cumplirían esa condición (Tabla 3), por lo que la cifra ascendería a 40 lotes con claras probabilidades de fracasar o de obtener escasos beneficios como para mantener a una familia.

\section{GRÁFICO 2}

Distribución porcentual de la cobertura del suelo de la Sierra de Salinas antes de la ejecución del proyecto de colonización agraria

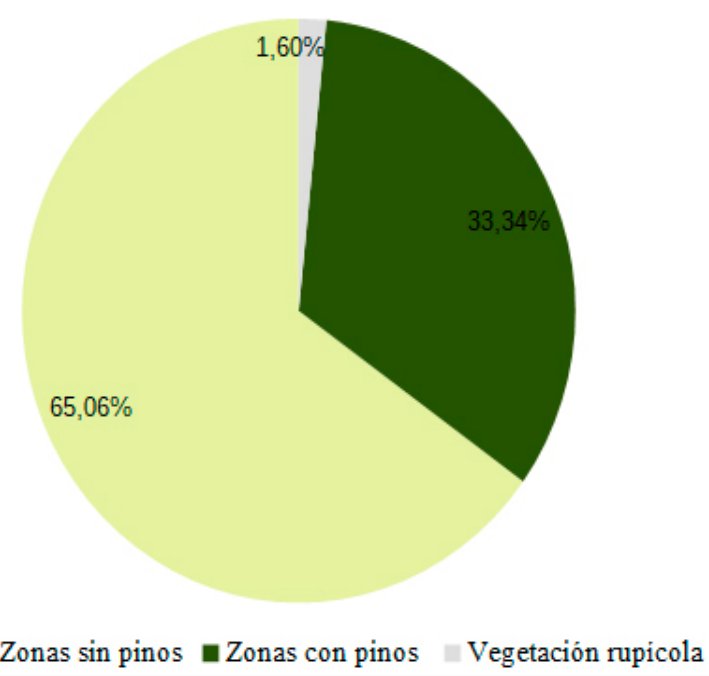

Fuente: Junta Central de Colonización y Repoblación Interior (1910). Elaboración propia. 
Ascensión Padilla, Juan Antonio Marco, Pablo Giménez y Ángel Sánchez

TABLA 2

Número de lotes según la calidad de las tierras en la tabla del proyecto de colonización agraria

\begin{tabular}{|l|c|c|c|}
\hline Calidad de las tierras agrícolas & $\begin{array}{c}\text { Superficie total } \\
\text { (ha) }\end{array}$ & $\begin{array}{c}\text { Tamaño de los lotes } \\
\text { (ha) }\end{array}$ & $\begin{array}{c}\text { Número de } \\
\text { lotes }\end{array}$ \\
\hline $1^{\text {a }}$ categoría & 23,5076 & 7,5699 & 3,11 \\
\hline $2^{\text {a }}$ categoría & 147,0636 & 11,251 & 13,07 \\
\hline $3^{\text {a }}$ categoría & 674,6122 & 20,4392 & 33,01 \\
\hline TOTAL & 845,1834 & 13,08 (tamaño medio) & 49,19 \\
\hline
\end{tabular}

Fuente: Junta Central de Colonización y Repoblación Interior (1910). Elaboración propia.

TABLA 3

Número de lotes según la calidad de las tierras en el texto del proyecto de colonización agraria

\begin{tabular}{|l|c|c|c|}
\hline Calidad de las tierras agrícolas & $\begin{array}{c}\text { Superficie total } \\
\text { (ha) }\end{array}$ & $\begin{array}{c}\text { Tamaño de los lotes } \\
\text { (ha) }\end{array}$ & $\begin{array}{c}\text { Número de } \\
\text { lotes }\end{array}$ \\
\hline $1^{\text {a }}$ categoría & 13,9528 & 7,5699 & 1,84 \\
\hline $2^{\text {a }}$ categoría & 83,5336 & 11,251 & 7,42 \\
\hline TOTAL & 97,4864 & 9,41 (tamaño medio) & 9,26 \\
\hline
\end{tabular}

Fuente: Junta Central de Colonización y Repoblación Interior (1910). Elaboración propia.

\subsection{Lo «inhabitable» de la Colonia Agrícola de la Sierra de Salinas}

Justificar las dificultades que ofrece este medio para su puesta en cultivo requeriría un estudio detallado sobre las características del medio físico que no es el objetivo de esta investigación. Pero, pensemos, por un momento, que dicho proyecto es una propuesta elaborada en la actualidad y requiere su análisis para determinar su viabilidad. En este caso, los técnicos de la Conselleria de Agricultura, Desarrollo Rural, Emergencia Climática y Transición Ecológica de la Generalitat Valenciana consultarían las capas de información disponibles en la IDEV. Es cierto que la cartografía existente en esta plataforma no es la más adecuada para estudios de detalle, como es el caso que nos ocupa en esta investigación; pero es el procedimiento que se llevaría a cabo en la administración pública.

La referencia cartográfica disponible para considerar la viabilidad del proyecto es la capacidad de usos del suelo, elaborada teniendo en cuenta los siguientes parámetros: régimen pluviométrico y térmico y de cómo pueden influir en el crecimiento vegetal; pendiente calculada en un valor porcentual; pedregosidad superficial, presencia de litosuelos y afloramientos rocosos que puedan dificultar el desarrollo del aparato radicular; espesor edáfico fértil; propiedades físicas y químicas del suelo (textura, hidromorfía, alcalinidad, salinidad); riesgos de 
erosión y de inundación (AÑó et al., 2002: 107). Se establecen cinco categorías de capacidad: muy elevada, elevada, moderada, baja y muy baja.

La elaboración de esta cartografía fue realizada en 1992 por la entonces denominada Conselleria de Obras Públicas, Urbanismo y Transportes (COPUT) a una escala de trabajo 1:50.000, poco apropiada para un estudio en detalle de esta área de estudio, como se ha indicado anteriormente. De hecho, podemos constatar que el área clasificada con una mayor capacidad agrícola, moderada, podría incluir tanto la primera categoría como la segunda de las unidades, definidas en el informe técnico de 1910, como "parcelas colonizables para el cultivo agrario», con y sin pinos, puesto que la superficie resultante es similar (Tabla 4). Se trata de una hipótesis ya que la memoria del proyecto no nos indica la ubicación de dichas parcelas; únicamente, se dispone de la referencia textual para las escasas hectáreas caracterizadas como totalmente fértiles, que las localiza en el fondo del valle.

TABLA 4

Comparativa de las superficies con capacidad agrícola y número de lotes resultantes

\begin{tabular}{|c|c|c|}
\hline Fuente de datos & Superficie (ha) & Número de lotes \\
\hline Tabla del proyecto & 170,5712 & 16,18 \\
\hline Memoria del proyecto & 97,4864 & 9,26 \\
\hline COPUT & 75,8 & 8 prácticamente completos \\
\cline { 2 - 3 } & 104,19 & 17 incompletos \\
\hline COPUT total & 179,99 & 25 \\
\hline
\end{tabular}

Fuente: Junta Central de Colonización y Repoblación Interior (1910) e IDEV. Elaboración propia.

Según la valoración realizada por la COPUT (Figura 4), podemos observar que la superficie de clase $C$ se ubica en el fondo del valle y laderas circundantes, pero también en la vertiente septentrional de la superficie de la colonia. Se califica a estas tierras de calidad moderada, lo que se traduce en un espesor edáfico de 30$50 \mathrm{~cm}$, salinidad de 4-8 dS/m, alcalinidad de 8-11 \%, textura franco-arenosa (AÑó et al., 2002: 109 y 111), pedregosidad en torno al 50\% y una pendiente inferior al $25 \%$ (figura 5). El resto de la superficie de la colonia se engloba en una baja capacidad de uso agrario aunque, considerando la existencia de pendientes con laderas por encima del 50\% (Figura 5), elevada pedregosidad y presencia de litosuelos, seguramente parte de ella debería de ser incluida en la categoría de muy baja potencialidad agrícola.

La superposición de la cartografía oficial de la COPUT sobre la capacidad de uso del suelo con la planimetría de la memoria del proyecto de colonización agraria de la Sierra de Salinas, permite conocer qué lotes son los más fértiles y, por tanto, viables (Figura 6). Aquellos íntegramente incluidos, o por encima de un $90 \%$ de su área, dentro de la categoría de capacidad moderada suman una superficie de 75,8 ha que se corresponden con 8 lotes. Esta cifra podríamos 
relacionarla con las tierras realmente fértiles que describe el texto de la memoria del proyecto (Tabla 4).

Por lo tanto, hoy en día, el proyecto de colonización agraria sólo sería considerado viable en el fondo del valle y vertiente septentrional de la colonia; pero con importantes reservas, ya que no se trata de un suelo fértil y apto para el cultivo. De hecho, esos son los lotes que han permanecido con actividad agrícola hasta el siglo XXI, el resto fueron todos abandonados. Con ello, se confirman los resultados expuestos en el apartado anterior.

\subsection{Cómo construir un paisaje aterrazado habitable en la Colonia Agrícola de la Sierra de Salinas}

La entrega de los 49 lotes no estuvo exenta de dificultades puesto que fue necesario repetir el sorteo entre los solicitantes ya que, o bien renunciaron, o no se presentaron. Por lo tanto, la primera se efectuó el 21 de abril ( 35 colonos) y la segunda el 19 de julio de 1914 (15 colonos). Solo unos pocos sabían escribir o, al menos, hacer su firma para poder plasmarla en la escritura (Figura 7) que recibían en el acto de entrega de los lotes. En la primera fecha, se dio a la cooperativa un documento en el que se indicaba el coste de la construcción de los edificios (308.020,86 ptas.) y el capital que adelantaba la Junta Central de Colonización para la puesta en funcionamiento de la Colonia Agrícola (144.607,74 ptas); es decir, para hacer frente en los tres primeros años a la compra de semillas, ganado de labor, aperos, creación del viñedo y del olivar, puesta en funcionamiento del campo experimental, adquisición del mobiliario de la iglesia y de la escuela y, la cantidad restante, como anticipo para los colonos para afrontar sus primeros gastos (MuÑOZ, s. f.).

Las duras condiciones del trabajo eran más que evidentes si se conocía la sierra. Incluso, se produjeron permutas en los casos de haber recibido un lote de peores características que aquellos que no fueron adjudicados por las causas anteriormente expuestas (CANALES, 1986: 44). Dichas permutas se efectuaron antes del segundo sorteo. Por lo tanto, podemos deducir que las familias que aceptaron trabajar los terrenos de peor calidad fue porque, realmente, eran "totalmente pobres» según rezaba la ley de 1907. Condición que, en realidad, se puede hacer extensiva a todos los colonos puesto que, en las solicitudes recibidas por la Junta Central de Colonización, se puede leer «jornalero agrícola pobre absolutamente». Como todos ellos se ajustaban a este requisito, fue necesario aplicar otros, que debían de cumplir los colonos según la ley, para poder realizar la selección: si estaban casados, si eran viudos o viudas con descendencia, el número de hijos y de hijas, si estos podían trabajar ya la tierra y si procedían del municipio de Villena (MuÑoz, s. f.).

Por este mismo motivo, se puede deducir que nada más entregados los lotes, las familias se dedicaron a transformar el territorio $\mathrm{y}$, en muchos casos, constataron que era imposible cumplir al 100\% lo planificado y cartografiado por el ingeniero agrónomo Luis Beneyto. De la superficie proyectada y distribución de lotes y de coberturas del suelo a la realidad hay una notable diferencia, según han informado los descendientes de los primeros colonos, pero este aspecto será tratado con más detenimiento en otro estudio. La "relativa rapidez» de la transformación y puesta en cultivo estuvo condicionada por las características del 
terreno; por tanto, las primeras en estar preparadas para su aprovechamiento y en dar beneficios fueron las del fondo del valle. A finales de 1920 solo se habían roturado 250 hectáreas (MuÑoz, s. f.) y la máxima población y total ocupación de los 49 lotes fue en 1923 según el Nomenclator de la Colonia y en el Padrón de Villena (TARRUELLA, 1998: 490-491).

Respecto a los cultivos, la memoria establecía que los idóneos eran el olivo (Olea europaea subsp. angustifolia), la vid (Vitis vitifera), el trigo rojo o grochal y la cebada común. La introducción sería paulatina para ir enriqueciendo las escasas propiedades edáficas del terreno; de modo que se cultivarían vid y cereal a partes iguales y, al quinto o sexto año, en la parte dedicada a las gramíneas se combinaría con olivo. Finalmente, habría 70 pies de olivo y 820 pies de vid por cada media hectárea y presencia de cereal en la otra media. Esta proporción se usó para determinar los beneficios que daría cada lote y para fijar su tamaño, según la calidad del terreno. En dicho cálculo también se tenía en cuenta el abono necesario, la fuerza animal para arar y cosechar, coste de las semillas, jornales e impuestos por cada hectárea (Junta Central de Colonización y Repoblación Interior, 1910). Igual que no se transformaron todas las hectáreas «cultivables» de cada lote, tampoco se siguieron a rajatabla estas pautas, según nos han informado los actuales colonos.

Se cultivó trigo, centeno, avena, cebada, guija o Lathyrus sp., cáñamo y judías (CARPENA et al., 2017: 85-86), patatas, tomates y otras hortalizas para poder comer hasta que los olivos y la vid empezaran a producir, a partir de los cinco o seis años de ser plantados, teniendo en cuenta que, en algunos lotes, podría tardar más por la mala calidad de los suelos. Según las actas de la cooperativa, en 1919 cada colono tenía ya plantados 700 olivos; sin embargo, no había nada de viña. Por este motivo, se les obligó a ahoyar 2000 vides al siguiente año. Estos registros demuestran el seguimiento que realizaba la cooperativa de cada colono, ya que no solo se anotaba lo plantado y producido o la deuda y el crédito, sino también si había trabajado en el lote, arado, etc. También se poseía algo de ganado: gallinas, conejos, cerdos y cabras, aunque casi no hay información al respecto (MUÑOz, s. f.).

La parcela de experimentación junto a la zona comunal, podía facilitar la selección de semillas o de cultivos; si bien es cierto que ésta se localizaba en la zona más fértil de toda la colonia por lo que de poco podía servir para los lotes ubicados en las áreas más pedregosas y de $3^{a}$ categoría. El ingeniero agrónomo de la colonia era el encargado de realizar estas experimentaciones y de aconsejar los cultivos o variedades dependiendo de las condiciones climáticas o diferencias térmicas que pudiera observar en la colonia. Así, por ejemplo, en 1924, Francisco Candela, ingeniero director de la colonia, observó que no era conveniente compartir en las parcelas la superficie de cereal con el olivo por la excesiva humedad atmosférica; al igual que desaconsejaba el cultivo de alfalfa, lentejas, garbanzos, patatas, judías o guisantes por la escasa productividad. Por el contrario, el éxito obtenido en la parcela de experimentación con algunos alimentos para el ganado como la esparceta (Onobrychis viciifolia) o condimentos y especias como el azafrán o el zumaque (Rhus coriaria), le hizo aconsejarlos (MuÑoz, s. f.).

La construcción de todos los edificios de la colonia fue subastada y se adjudicaron el 21 de octubre de 1911 a D. Enrique Moragues Moncho, vecino de Valencia, por un importe total de 308.309 pesetas. En el proyecto, la zona comunal estaba constituida por la parcela experimental junto a una serie de edificios: sala de 
juntas y almacén; casa del guarda, igual que la de los colonos pero con cobertizos más amplios; iglesia; escuela, casa del vicario y maestro; una almazara; dos bodegas para vino (Figura 8). En 1920, se construyó un nuevo almacén porque el existente resultó de escasa capacidad; sin embargo, la almazara y las dos bodegas no llegaron a edificarse (MuÑz, s. f.).

El plano de las casas descrito en la memoria era común para todos los lotes. Las dimensiones eran de 9,25 metros de largo por 8 metros de ancho y 5 metros de alto. Tenían dos plantas: la parte inferior fue destinada a la vivienda y la superior al granero y almacén (CANALES, 1986). El corral y las cuadras estaban adosados a la edificación anterior. Todas las viviendas disponían de horno y aljibe (Figura 9). Uno de los grandes problemas de la Sierra de Salinas era la falta de agua. La dependencia de las lluvias era grande y los aljibes no se llenaban nunca. Las fuentes que tenían caudal entonces eran: El Pozuelo, la de más caudal incluso hoy en día, La Fuente del Lobo, pequeño pozo artesiano que apenas se usaba; la del Rincón y la de Enmedio, ambas secas en la actualidad.

Dos eran los órganos de gobierno en la Colonia Agrícola: Consejo de Administración y la Junta General de Colonos. El primero estaba constituido por el presidente de la cooperativa y director de la colonia que era nombrado por la Junta Central de Colonización y era un delegado suyo, seis colonos y el secretario-contador que era el maestro de la colonia, con voz pero sin voto y que se encargaba de los libros de contabilidad. La segunda estaba compuesta por los 49 colonos y se reunían al menos una vez al año. Las funciones de la Junta era comprar los beneficios de los colonos y a cambio se les entregaba unos vales de producción; obtener productos básicos (comestibles, de primera necesidad o para los cultivos y labranza) que se compraban con los mencionados vales; repoblación y aprovechamiento forestal; y concesión de créditos a los colonos (MuÑoz, s. f.). La figura del guarda también era importante, ya que era el encargado de vigilar los montes y su correcto aprovechamiento forestal, además de aportar seguridad. En años en los que el clima no era favorable para el cultivo y con el fin de poder dar de comer a su familia, se hacían sacas ilegales de leña; por esta circunstancia, la figura del guarda era relevante. Uno de ellos fue Francisco Soriano Muñoz (Figura 10) que, incluso, impartió docencia en momentos en los que no existía profesorado en la Colonia.

La cooperativa y el área en común favoreció la vida de aquellos colonos con lotes de peor calidad, puesto que el aprovechamiento forestal del monte se repartía entre todos. A cada colono se le asignaba una libreta en la que se llevaba un registro de lo gastado y producido: importe y número de los vales de consumo y producción, los créditos recibidos y el saldo. En 1924, se reguló este funcionamiento y se sustituyeron las libretas por cupones de crédito por el valor disponible de cada colono en la cooperativa (MuÑoz, s. f.).

Los testimonios de los descendientes confirman que las tierras no eran muy productivas y que algunos llegaban a hacer trueque con campesinos de fuera de la colonia donde las tierras eran mucho mejores; por ejemplo, se menciona la «riqueza» del municipio vecino de El Pinós «donde había arroz, acelgas, allí había de todo» ${ }^{4}$ y se canjeaba por tabaco que cultivaban algunos de los colonos. La cooperación en las tareas agrícolas era normal, por ejemplo, en momentos de siega, trilla del cereal; así como en la matanza del cerdo a finales de diciembre o

4 Sierra de Salinas Tierra de Colonos (1914-2014) [en línea]. Disponible en: https://www.youtube. com/watch?time_continue $=9 \& v=U C 6030 P 9 f-8 \&$ feature $=$ emb_logo [Consulta: $17 / 09 / 2020$ ]. 
principios de enero.

El abono era necesario por la mala calidad de las tierras. Unos cuatro o cinco colonos bajaban en carro y mula hasta Villena donde lo adquirían. La distancia se medía en tiempo y no en kilómetros: cuatro horas. Al llegar a la zona común de la colonia, había que transportarlo hasta cada lote. Debido a las cuestas, al mal estado de algunos caminos y al peso del cargamento, era necesario poner más mulas en cada carro para que pudieran tirar de ellos. Esta tarea requería también la cooperación, al igual que el mantenimiento de los accesos. Los baches eran arreglados por varios colonos durante los domingos: se llenaban con romero y se cubrían de tierra para allanar la carretera.

La vida en la colonia estaba destinada, como en el resto del mundo agrario, al trabajo de la tierra, cuidado del ganado y tareas domésticas, por lo que había poco tiempo libre. Si lo había, los hombres se dedicaban a la caza o se organizaban reuniones entre las casas más cercanas los domingos por la tarde cuando empezaba a caer el sol. Los hombres jugaban a las cartas, al truque, y las mujeres «a charrar», se contaban chismes o anécdotas, los pequeños a jugar a la calle y los jóvenes iban a la escuela, apartaban los pupitres y se hacía baile y se cantaba al son de la guitarra o del acordeón. Se solían juntar cada vez en una casa y se aportaba para cenar lo que se podía. Celebraciones había pocas, fundamentalmente las religiosas: bodas, bautizos, comuniones y entierros, la Pascua o también las matanzas (Figura 11). Es curioso que los descendientes más mayores siguen hablando de los colonos de arriba y de los de abajo, haciendo referencia a los lotes de mayor altitud y a los del fondo del valle. También reconocen el mayor aislamiento y dificultades que tenían los primeros debido al mal estado de los caminos y por tener las peores tierras.

Ir a la escuela era casi imposible ya que los niños y las niñas trabajan por las mañanas hasta el atardecer de lunes a domingo, como describe y recuerda un colono cuando revive su infancia en los años 1920: «trasegar el vino, hacer la trilla y pasar la tabla por la era» (MuÑOz, s. f.). Era al caer el sol cuando acudían. Regresaban a sus casas ya de noche a oscuras, guiados por el reflejo de la luna o por un candil. No todos los caminos eran muy transitables, como ya se ha indicado, sólo los principales que databan de hacía siglos cuando el único aprovechamiento de esta sierra era el forestal. Las clases se impartían a la luz de la lámpara de carburo.

El elevado absentismo determinó que, el 1 de julio de 1932, el pleno municipal de Villena solicitase el traslado de la escuela de la colonia al caserío de La Encina, pero no llegó a producirse, ya que los colonos presentaron un escrito para enviarlo al Director General de Primera Enseñanza. El maestro o la maestra dependían de la Junta de Colonización hasta agosto de 1927, fecha en la que por Real Orden pasaron a depender del Estado todos los centros educativos de las colonias agrícolas. Durante la guerra civil, evidentemente, se suspendieron las clases y no se retomaron hasta mediados o finales de los años cuarenta. El último censo conocido es de 1961, con 12 estudiantes (4 niñas y 8 niños) y la última maestra fue Dña. Elia Navajas. Aquellos cuyos lotes se ubicaban fuera del valle, más próximo al término municipal de Yecla, no asistían a la escuela de la colonia, sino que iban a la finca de El Portichuelo, donde acudía un maestro, a unos dos o tres kilómetros de sus casas, pero de más fácil acceso y menor distancia que la escuela de la zona comunal.

El espíritu colonial con el que se creó sigue vigente en sus descendientes, 
hasta los más jóvenes, ya de sexta generación. Este sentimiento de cooperación es lo que más recalcan en las entrevistas. Es manifiesto el orgullo por su historia y por sentirse colono. Reconocen la necesidad de adaptarse a la actualidad como, por ejemplo, adecuar las casas con energía solar por la falta de electricidad; el problema de la falta de agua, limitada a los aljibes; el mal estado de los caminos o la imperiosa necesidad de mantener limpio el pinar porque es un riesgo evidente ante la posibilidad de que se produjera un incendio forestal.

\section{CONCLUSIONES}

En el desarrollo argumental de esta investigación ha quedado claramente manifiesta la no viabilidad del proyecto de colonización agrícola de la Sierra de Salinas, excepto en el sector denominado como fondo de valle y las laderas septentrionales del límite superior de la colonia. Las diferencias topográficas, litológicas, edáficas, incluso climáticas, son evidentes: un espacio mayoritario claramente forestal y otro, más reducido, medianamente agrícola (Figura 13). Su ejecución, pese a que la lectura entre líneas de la memoria o informe técnico evidenciaban la realidad, tampoco nos debe de alarmar, ni siquiera que se antepusieran intereses políticos al bienestar del colono y su familia que, ya de por sí, era «jornalero agrícola pobre absolutamente». A lo largo de la historia y en la actualidad son muchos los ejemplos con este cariz. El valor de este caso es cómo, pese a la adversidad, se construyó una comunidad que sigue viva después de seis generaciones y, desde 1914 hasta hoy, se alimentó lo que sus descendientes llaman «el espíritu de la colonia». Pero, además, se edificó un paisaje antropogénico de gran valía patrimonial ligada al aprovechamiento agrario, con la presencia patente de la piedra seca en los muretes creados entre bancales y en los de las eras (Figura 13). Este tipo de construcciones han sido reconocidas y consideradas como patrimonio inmaterial de la humanidad por la UNESCO en 2018.

Por otra parte, hay otro aspecto que no era objeto de estudio en esta investigación, pero que en las conclusiones no se puede obviar y es la elevada biodiversidad y riqueza natural de este espacio. La colonia forma parte del LICES5213039 (92/43/CEE 21/05/1992) y ZEPA-ES0000457 (DOGV6031 09/06/2009 y DOCV6155 30/11/2009) de la Sierra de Salinas, aunque no tiene ninguna figura de protección salvo a escala de detalle: microrreserva de flora de la Cueva del Lagrimal (DOGV 3505 28/05/1999). Además, constituye un importantísimo corredor ecológico y biológico por su ubicación ecotónica ya que se encuentra entre tres provincias biogeográficas: catalano-valenciano-provenzal, castellanomaestrazgo-manchega y murciano-almeriense.

Las dificultades actuales a las que se enfrenta la Colonia Agrícola de la Sierra de Salinas son similares a las de principios del siglo xx. La falta de agua y de electricidad en las casas que se mantienen todavía en pie y que no fueron derribadas en 1977 por el Instituto Nacional de Reforma y Desarrollo Agrario (IRYDA) (TARRUELLA, 1998: 507) o una larga lucha con la administración pública por obtener la propiedad, reclamada en 37 lotes, que finalizó el 15 de abril del 2010, pero se reabrió con la inclusión de las zonas comunales y de algún lote sin propietario en el Catálogo de Montes de Dominio Público y Utilidad Pública de 
la Provincia de Alicante. ${ }^{5}$ Otras problemáticas que han surgido con el paso de los años son la escasa población residente permanentemente, solo 2 casas con un total de 3 personas, frente a la que hace uso de la vivienda para estancias esporádicas o de fin de semana; la densidad de la masa del pinar y su imperiosa necesidad de aclareo y limpieza; el elevado riesgo de incendio y de plagas; el mantenimiento del camino asfaltado principal y los numerosos de tierra; la necesidad de mano de obra para que siga trabajando la tierra con el fin de preservar la biodiversidad que aporta este mosaico paisajístico de alternancia de campos de cultivo, formaciones arbustivas, pinares monoespecíficos o con sotobosque de carrascas y vegetación rupícola; y, quizás, la que más temen los descendientes de aquellos y aquellas luchadoras de 1914, la pérdida del «espíritu de la colonia», puesto que ocho lotes han sido ya vendidos a personas externas del ámbito de la colonia.

Por esta última razón y con el fin de evitarlo, todos los años desde 2006 continúan festejando dos encuentros comunitarios: el Brindis de Navidad, en diciembre, y la Convivencia Anual, en junio, en la que se celebra el aniversario de la creación de la Colonia Agrícola de la Sierra de Salinas. Los actuales colonos reconocen que se han de abrir al exterior y darse a conocer, pero sin perder su identidad. De este modo, hay una colaboración con el ayuntamiento de Villena para crear un museo etnográfico en la casa del guarda y existe el proyecto de transformar algunas de las viviendas en casas rurales con el fin de introducir el ecoturismo en la colonia y de evitar que éstas se abandonen o tengan que venderse por no poder sufragar su mantenimiento.

La Colonia Agrícola de la Sierra de Salinas es un caso de estudio muy interesante por muchos motivos: históricos, culturales, sociales, económicos, florísticos o faunísticos son, quizás, los más destacados. Este trabajo se ha centrado en demostrar la inviabilidad del proyecto y en resaltar, fundamentalmente, la parte humana. De cómo los colonos construyeron, en pocos años, un paisaje agrario aterrazado habitable en un territorio poco propicio para ello y de cómo, sin saberlo, crearon un mosaico de texturas y hábitats que ha potenciado su biodiversidad, así como su valor ambiental, ya que roza la definición de un ecosistema sostenible. El reto es alcanzarlo y evitar que el abandono agrícola y forestal se generalice y se pierda esa diversidad paisajística que caracteriza y singulariza a este espacio.

\section{AGRADECIMIENTOS}

La autoría de esta investigación quiere agradecer especialmente la colaboración del presidente saliente, Andrés Lopez Estebán, y fundamentalmente del encargado del archivo y documentación de la Asociación de Colonos Agrícolas y Patrimonios Familiares de la Sierra de Salinas de Villena, Jerónimo Muñoz Forte por la documentación, testimonios orales, fotografías y enlaces a documentales facilitados.

5 Decreto 241/2015, de 29 diciembre, del Consell por el que se declara de utilidad pública el monte denominado Serra de Salinas, situado en el término municipal de Villena y propiedad de la Generalitat y se incluye en el Catálogo de Montes de Dominio Público y Utilidad Pública de la Provincia de Alicante. [2015/10465]. 


\section{REFERENCIAS}

AÑó, C.; SÁnCheZ, J.; ANTolín, C.; Goberna, M. (2002): «Capacidad y vulnerabilidad de los suelos de la Comunidad Valenciana», Investigaciones Geográficas, 28: 105-123. https:// doi.org/10.14198/INGEO2002.28.02.

Canales Martínez, G. (1986): «Sierra de Salinas: El fracaso de una colonización», Investigaciones geográficas, 4: 41-58.

Canales Martínez, G. (1998): «La colonización agraria en España y su incidencia en el poblamiento», en Diputación Provincial de Alicante (ed.), La población valenciana: pasado, presente y futuro, vol. I Instituto Juan Gil-Albert, Alicante: 345-366.

CARPENA, F.J.; CASTAÑo, J.; ANDRÉs, D. (2016): Aprovechamiento de los recursos naturales en una comarca histórica: Villena-Yecla (1700-1850), Fundación Municipal «José María Soler», Villena.

CARPena, F.J.; CASTAÑo, J.; ANDRÉS, D. (2017): «La descripción de Villena de 1771 en el “Correo General de España”. Edición comentada», Byliana, 2: 78-97.

IbÁÑ̃z MartíneZ, J. (1985): Los valles y las montañas de Villena, Ayuntamiento de Villena, Villena.

Junta Central de Colonización y Repoblación Interior (1910): Memoria y planos del proyecto de colonización del monte "Sierra de Salinas" del término de Villena (Alicante), Imp. de la Sucesora de M. Minuesa de los Rios, Madrid.

Ministerio de Agricultura, Pesca y Alimentación (1990): Clasificación general de los montes públicos 1859. Icona, Madrid.

Ministerio de Fomento (1907): Memoria sobre el Proyecto de ley de colonización interior. Madrid. Dirección General de Agricultura, Industria y Comercio.

Muñoz Forte, J. (s. f.): Textos de la Muestra etnográfica en la Casa del Guarda con motivo del centenario de la Colonia Sierra de Salinas, 1914-2014, Texto inédito, Villena.

Padilla Blanco, A. (2000): «Repercusiones en la cubierta vegetal de la política de colonización agrícola en la Sierra de Salinas (Alicante)», Cuadernos de Geografía, 67-68: 305-328.

Paniagua Mazorra, A. (1992): Repercusiones sociodemográficas de la política de colonización durante el siglo XIX y primer tercio del XX, Ministerio de Agricultura, Pesca y Alimentación, Secretaría General Técnica, Madrid.

TARRUELla RódenAS, M.J. (1998): «Evolución de la colonia agro-forestal: Sierra de Salinas (1914-1997)», en Diputación Provincial de Alicante (ed.) La población valenciana: pasado, presente y futuro, vol. I, Instituto Juan Gil-Albert, Alicante: 485-510. 
La construcción «exprés» de un paisaje aterrazado habitable...

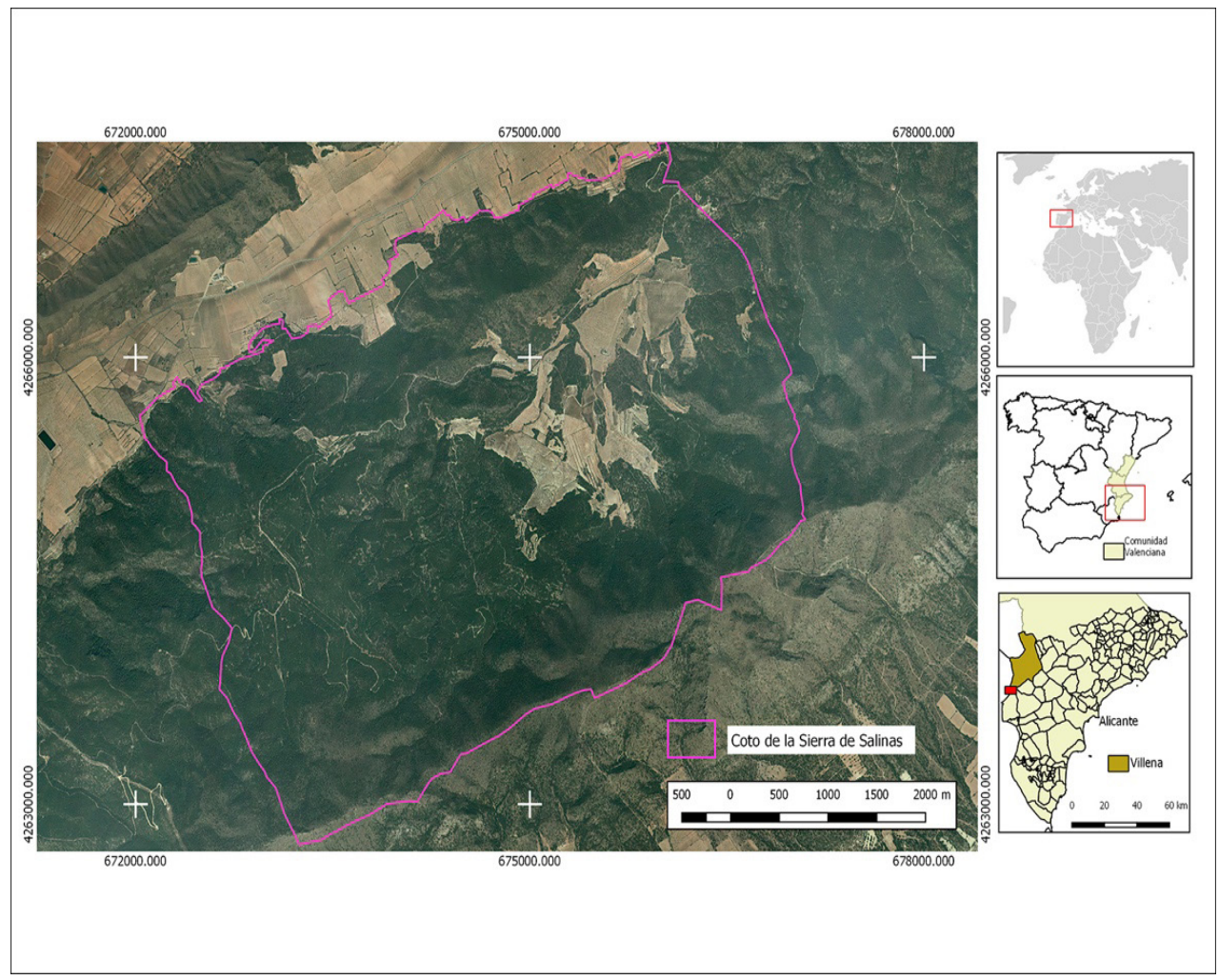

Figura 1. Localización de la Colonia Agrícola de la Sierra de Salinas. Fuente: PNOA y Asociación de Colonos Agrícolas y Patrimonios Familiares de la Sierra de Salinas de Villena. Elaboración propia. 
Ascensión Padilla, Juan Antonio Marco, Pablo Giménez y Ángel Sánchez

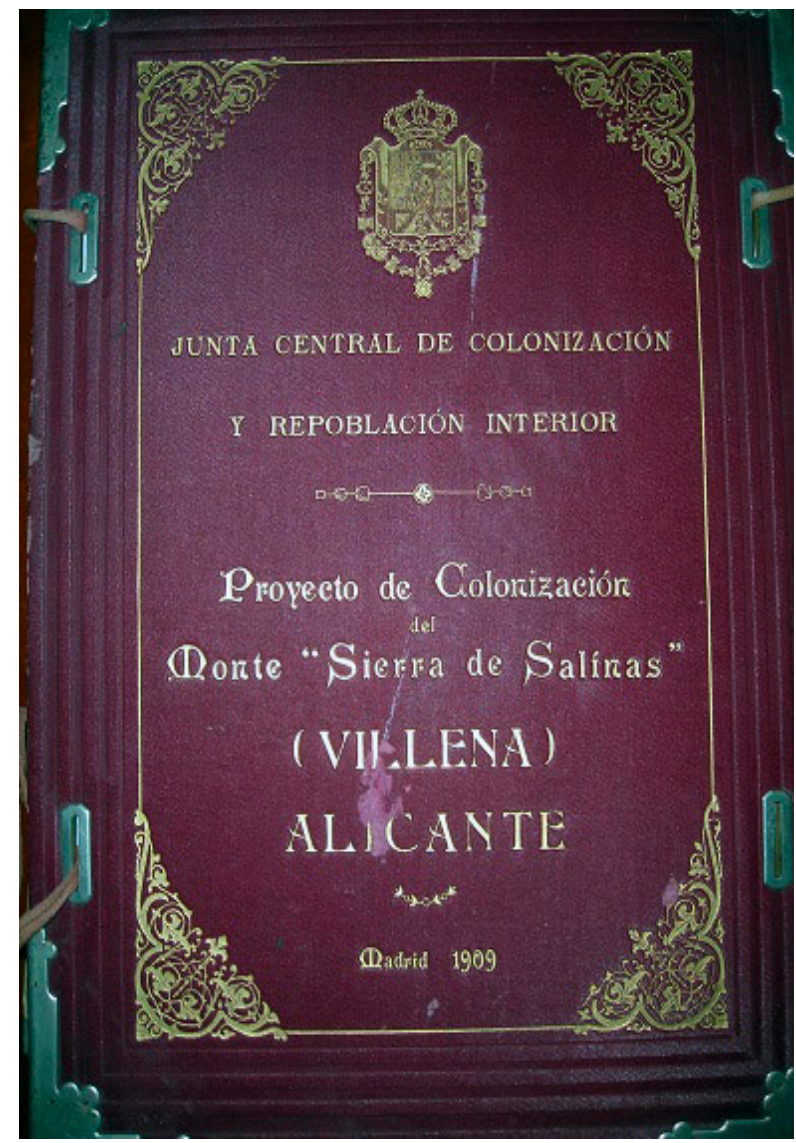

Figura 2. Portada del Proyecto de Colonización del Monte «Sierra de Salinas» (Villena) Alicante. (Asociación de Colonos Agrícolas y Patrimonios Familiares de la Sierra de Salinas de Villena) 
La construcción «exprés» de un paisaje aterrazado habitable...

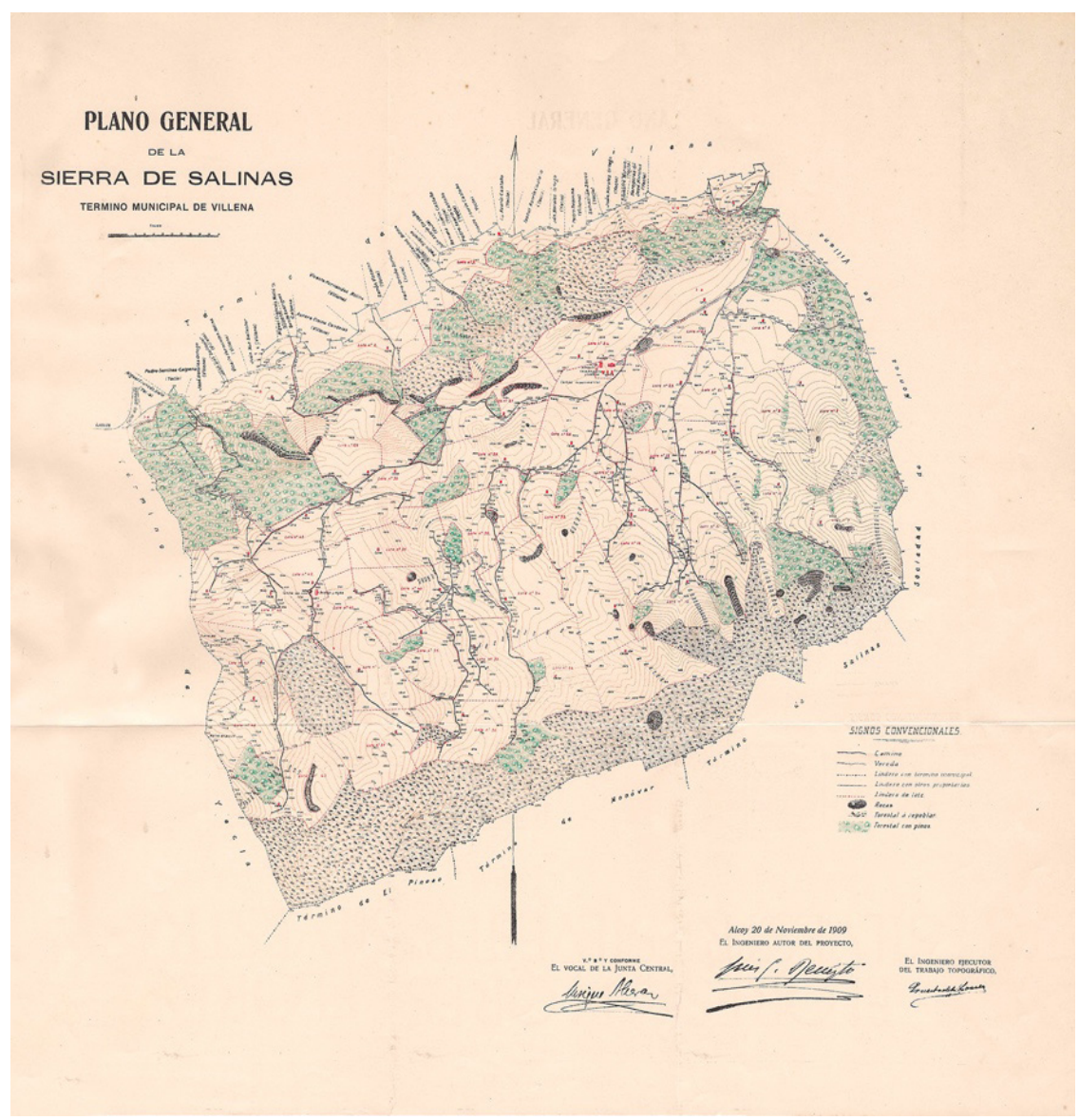

Figura 3. Plano con la distribución de lotes y de coberturas del suelo proyectadas en la transformación de este espacio. Fuente: Asociación de Colonos Agrícolas y Patrimonios Familiares de la Sierra de Salinas de Villena. 


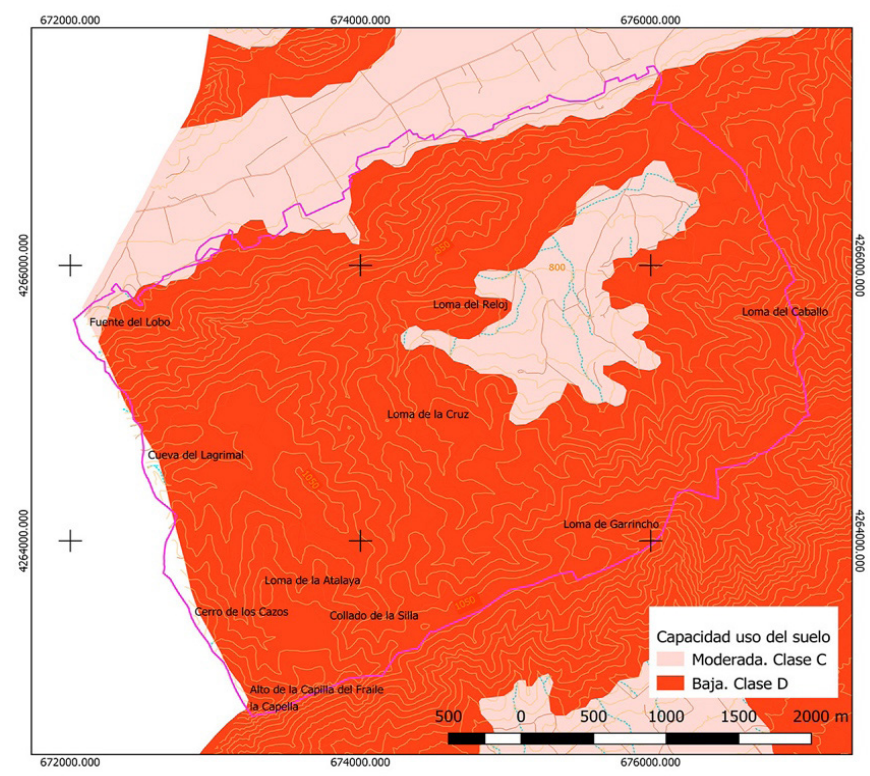

Figura 4. Capacidad de uso del suelo de la Colonia Agrícola de la Sierra de Salinas. Fuente: IDEV. Elaboración propia.

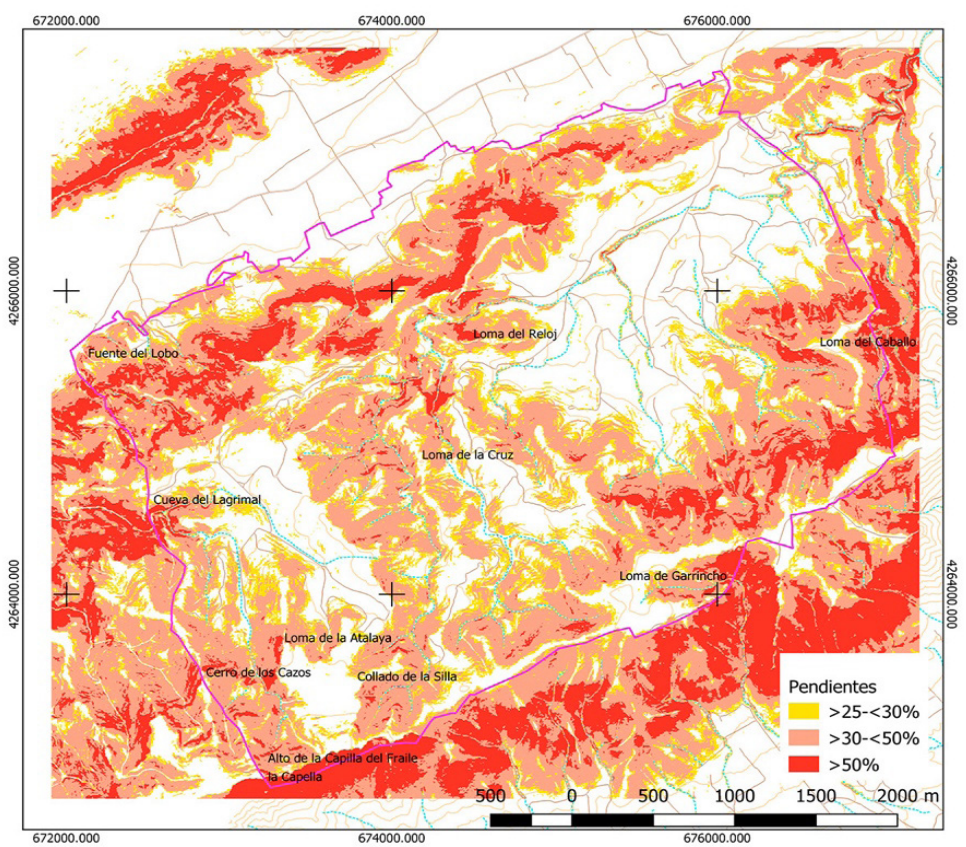

Figura 5. Pendientes en valor porcentual, Colonia Agrícola de la Sierra de Salinas. Fuente: IDEV. Elaboración propia. 
La construcción «exprés» de un paisaje aterrazado habitable...

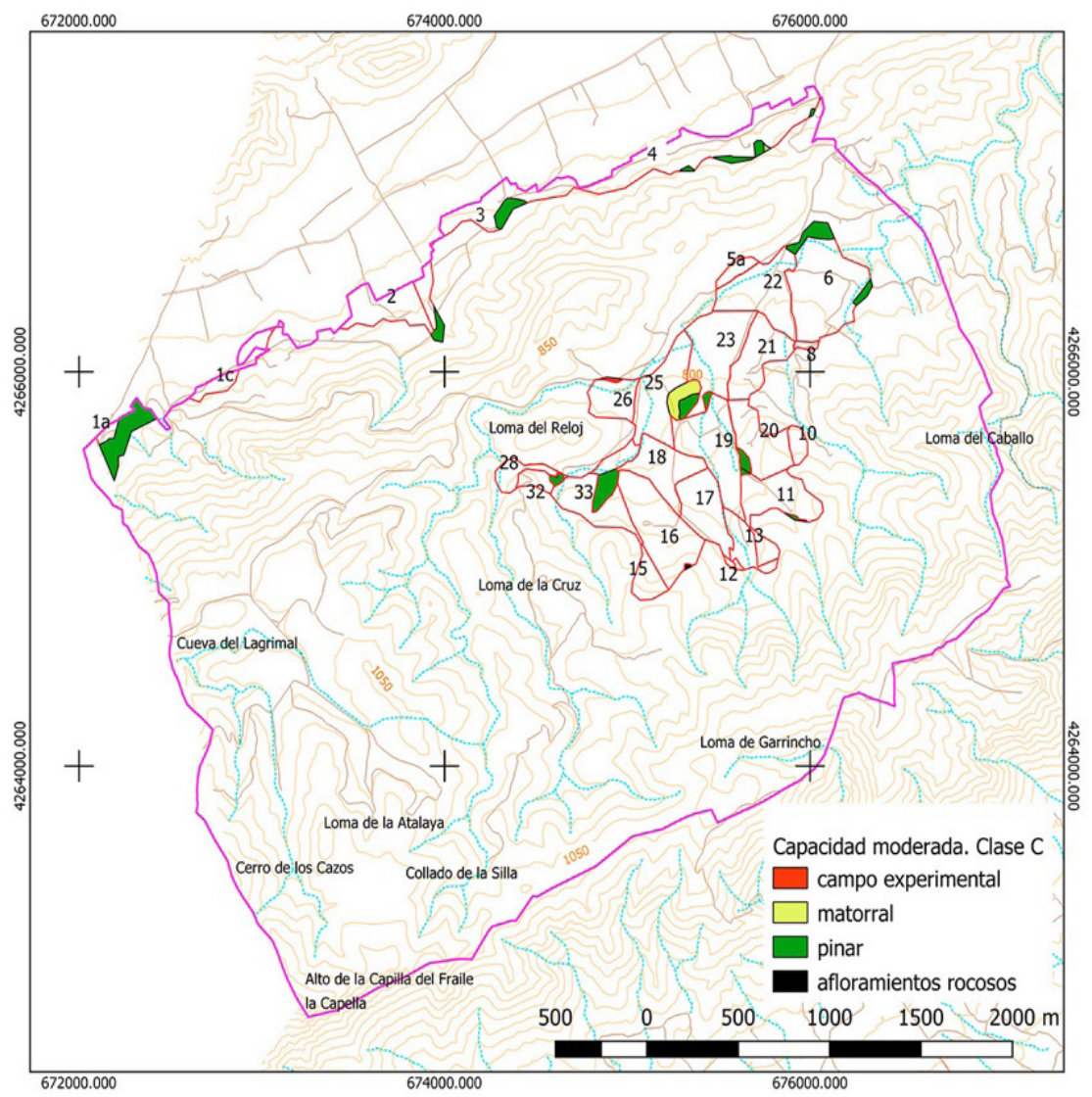

Figura 6. Lotes del proyecto de colonización insertos en la capacidad moderada de uso del suelo. Fuente: Junta Central de Colonización y Repoblación Interior (1910) e IDEV. Elaboración propia. 


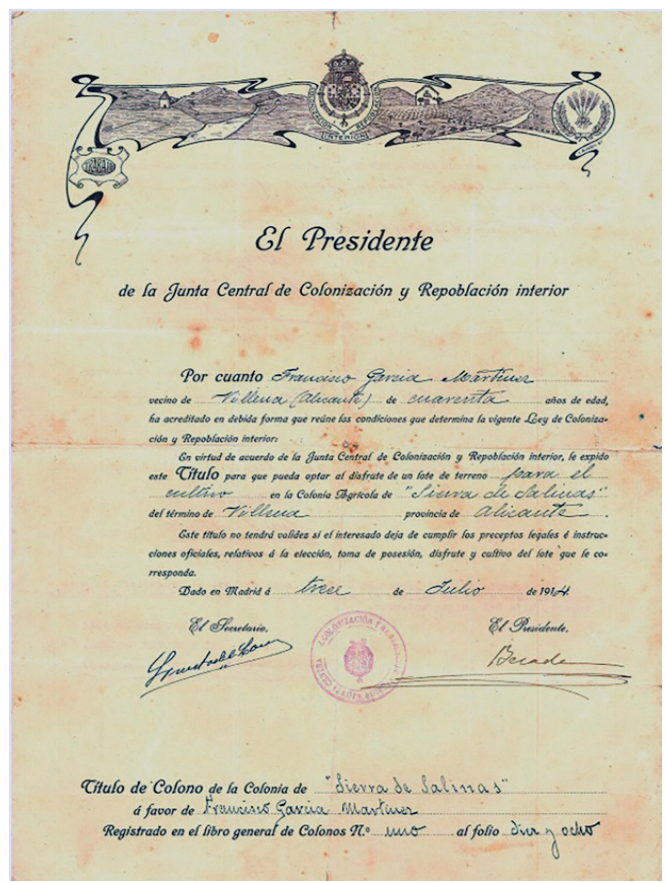

Figura 7. Título de propiedad de un lote agrícola de la colonia de la Sierra de Salinas. Fuente: Asociación de Colonos Agrícolas y Patrimonios Familiares de la Sierra de Salinas de Villena.

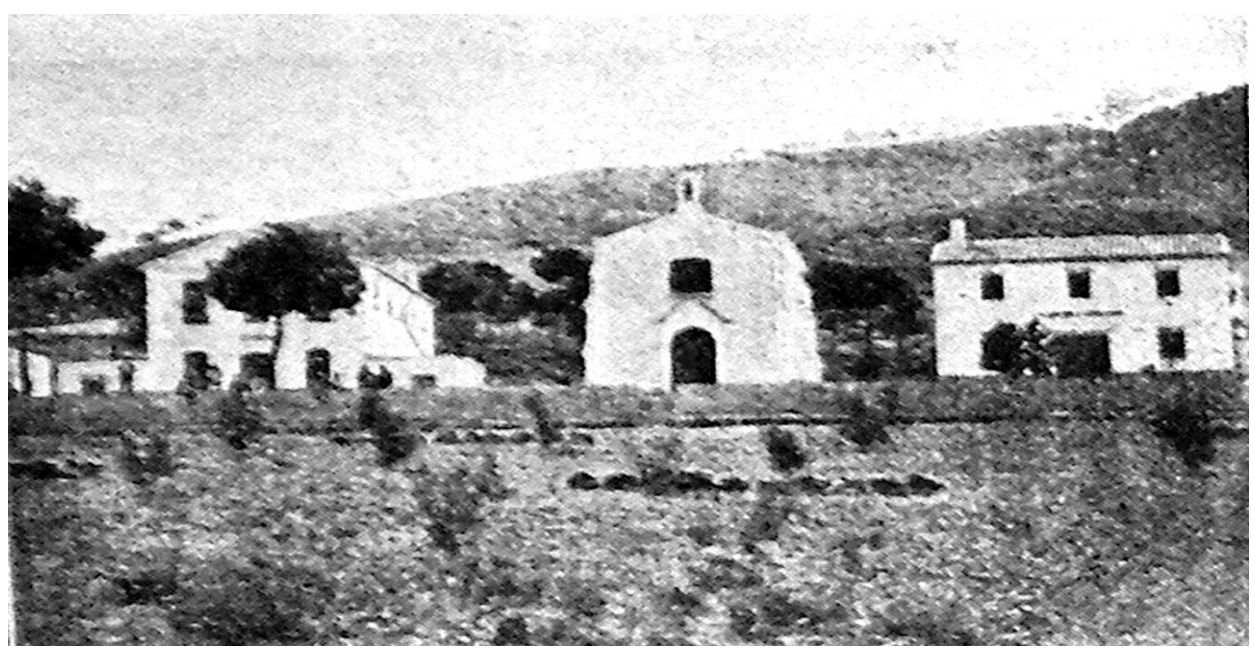

Figura 8. Edificios comunales (de izda. a dcha.) escuela, iglesia y sala de juntas-almacén. Año 1919. Fotografía: Asociación de Colonos Agrícolas y Patrimonios Familiares de la Sierra de Salinas de Villena. 
La construcción «exprés» de un paisaje aterrazado habitable...

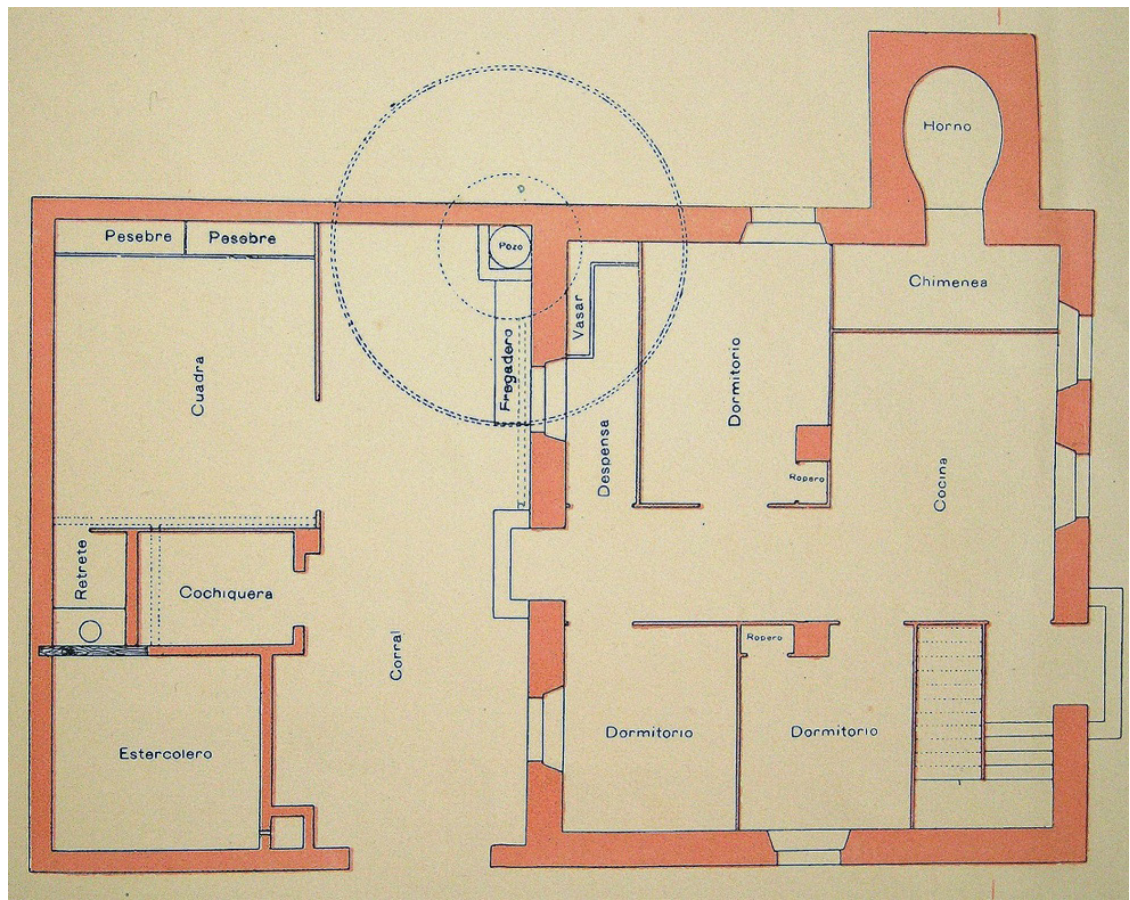

Figura 9. Plano de las casas de los colonos según el proyecto de colonización interior de la Sierra de Salinas. Fuente: Asociación de Colonos Agrícolas y Patrimonios Familiares de la Sierra de Salinas de Villena.
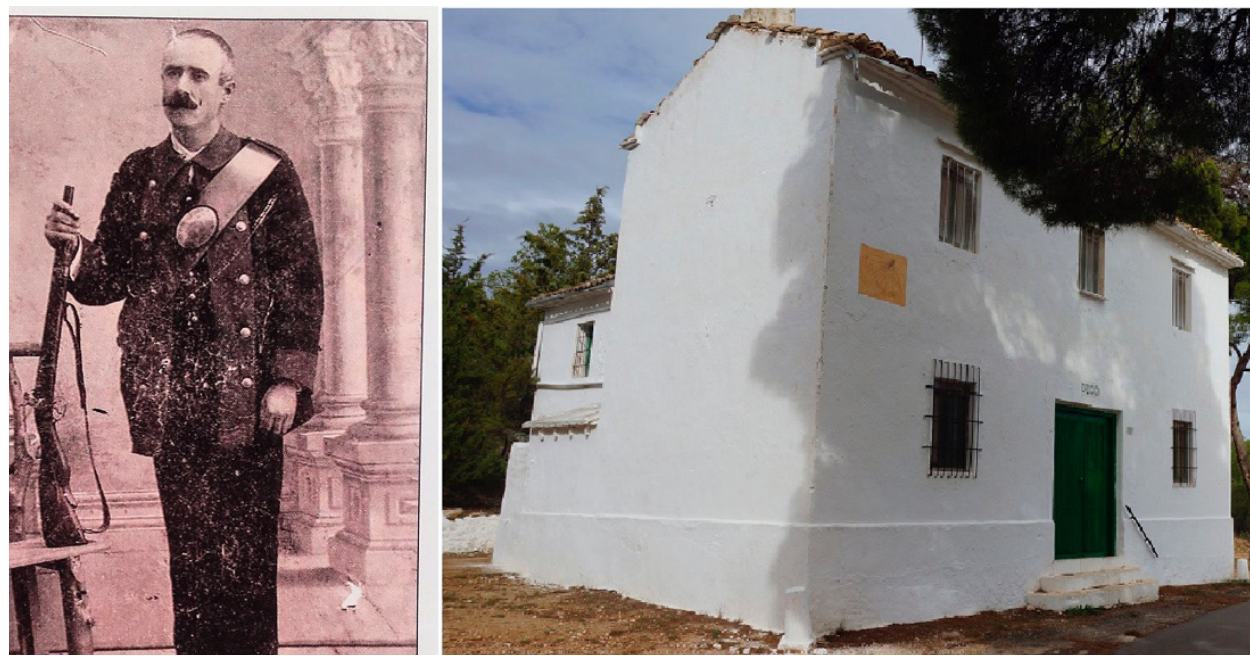

Figura 10. Guarda de la Colonia de Salinas (izquierda) y sala de juntas-almacén (derecha). Fotografías: Asociación de Colonos Agrícolas y Patrimonios Familiares de la Sierra de Salinas de Villena (izquierda) y elaboración propia (derecha). 


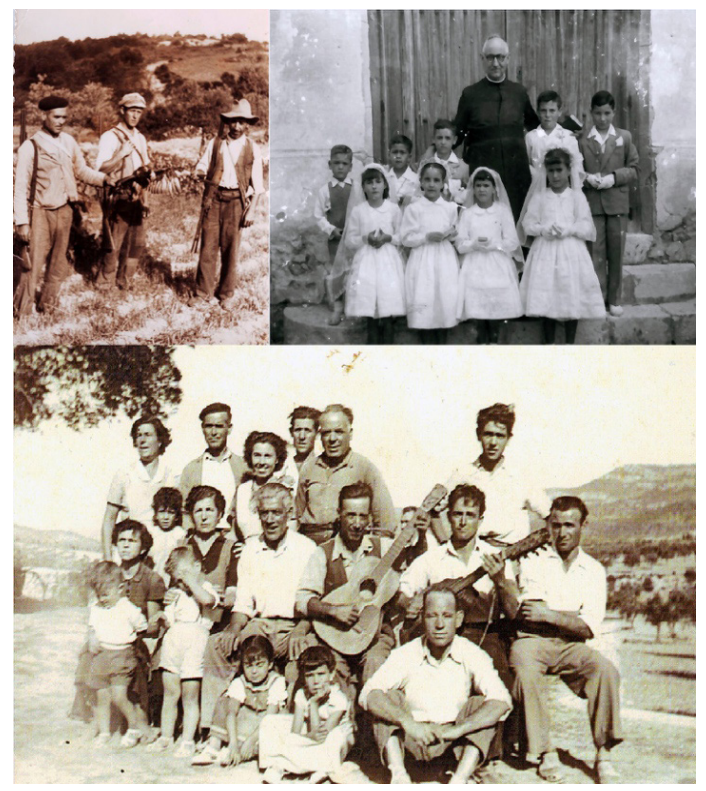

Figura 11. Momentos de la vida en la Colonia Agrícola de Salinas: caza, comunión y reuniones en las casas los domingos. Fotografías: Asociación de Colonos Agrícolas y Patrimonios Familiares de la Sierra de Salinas de Villena.

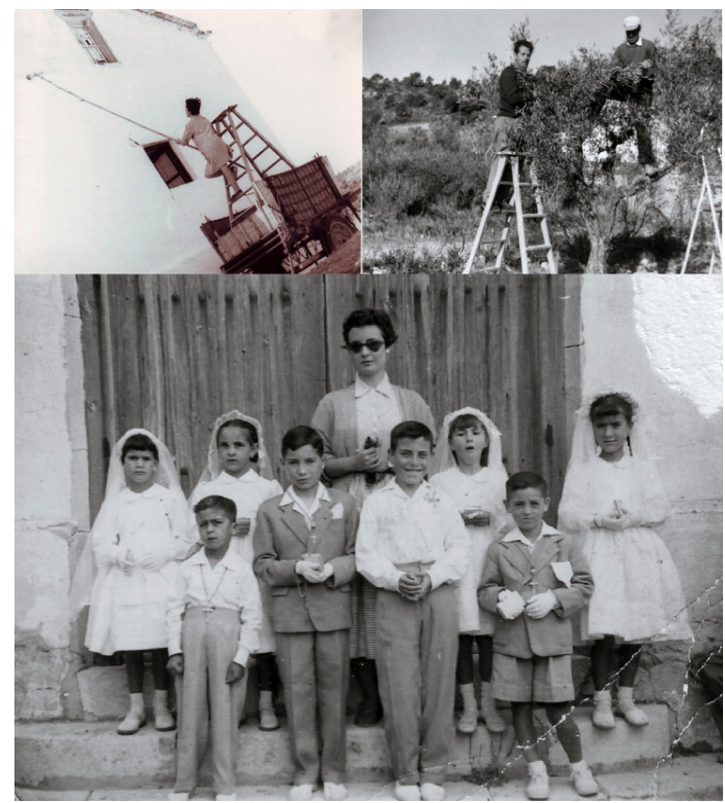

Figura 12. Momentos de la vida en la colonia agrícola de Salinas: encalando la casa de colonos, recogiendo la oliva y una comunión con la presencia de la maestra. Fotografías: Asociación de Colonos Agrícolas y Patrimonios Familiares de la Sierra de Salinas de Villena. 
La construcción «exprés» de un paisaje aterrazado habitable...

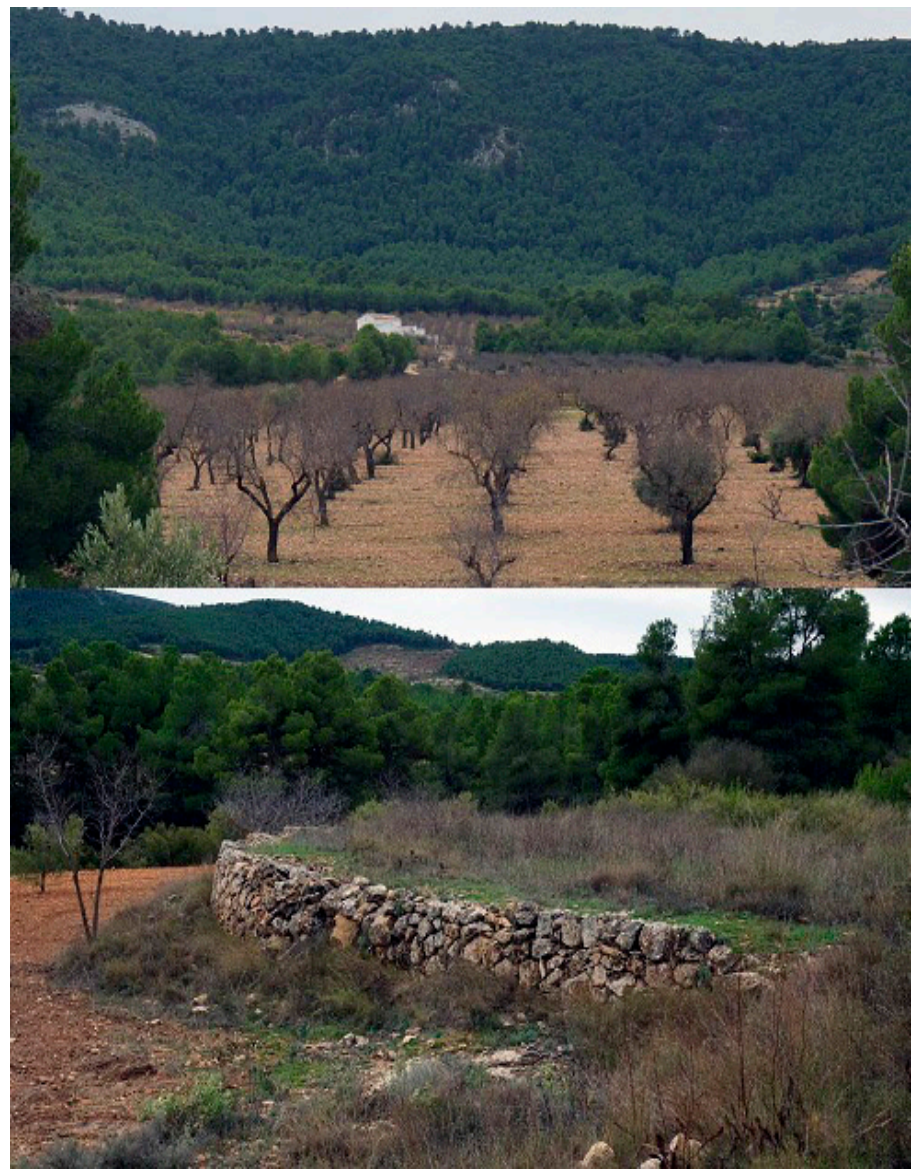

Figura 13. Vista desde el fondo del valle hacia la culminación de la Sierra de Salinas y detalle de muro de piedra seca de una era abandonada. Fotografía: elaboración propia. 